\title{
Erratum
}

\section{Erratum: Blood and Bone Marrow Transplantation in India: Past, Present, and Future}

In the article titled "Blood and Bone Marrow Transplantation in India: Past, Present, and Future", published on pages 308311, Issue 3, Volume 41 of Indian Journal of Medical and Paediatric Oncology ${ }^{[1]}$, the term transcatheter cardiovascular therapeutics (TCT) has been incorrectly mentioned on page 309 , under The future (2020 to eternity) paragraph, $4^{\text {th }}$ para, $14^{\text {th }}$ line. The correct term should be transplantation and cellular therapy (TCT).

\section{Reference}

1. Saikia TK. Blood and bone marrow transplantation in India: Past, present, and future. Indian J Med Paediatr Oncol 2020;41:308-11.

DOI: $10.4103 / 0971-5851.293846$ 